\title{
Venous Bypass in Clinical Liver Transplantation
}

BYERS W. SHAW, JR., M.D., DOUGLAS J. MARTIN, M.D.,† JOSE M. MARQUEZ, M.D., $\dagger$ Y. G. KANG, M.D., $\dagger$ ALAN C. BUGBEE, JR., PH.D.,† SHUNZABURO IWATSUKI, M.D.," BARTLEY P. GRIFFITH, M.D.," ROBERT L. HARDESTY, M.D.," HENRY T. BAHNSON, M.D.,* THOMAS E. STARZL, M.D., PH.D.*

A venous bypass technique (BP) that does not require the use of systemic anticoagulation is used routinely at our institution in all adult patients during the anhepatic phase of liver transplantation (LT). Complete cardiopulmonary profiles were obtained in a subset of 28 consecutive cases. During the anhepatic phase while on bypass, mean arterial pressure, central venous pressure, and pulmonary arterial wedge pressure were maintained at prehepatectomy levels. Oxygen consumption fell secondary to a decrease in temperature and the removal of the liver. Consequently, cardiac index fell without an increase in arterial-venous $\mathrm{O}_{2}$ content difference, reflecting adequate tissue oxygenation. Compared with 63 patients in a previous series given LT without bypass (NBP), the 57 total BP patients experienced better postoperative renal function $(p<0.001)$, required less blood use during surgery $(p<0.01$ ), and had better survival 30 days after LT. The equivalency of 90-day survival in these groups results from the lack of effect of BP on the long-term survival of patients considered at high risk for metabolic reasons. BP patients at high risk for technical considerations, however, survived LT whereas NBP patients did not. BP offers other advantages important in establishing LT as a service-oriented procedure.

$\mathrm{T}^{\mathrm{H}}$ HE DRAMATIC IMPACT of cyclosporine on survival following liver transplantation has been widely reported. $^{1-4}$ Yet despite extensive experience with the operation during the preceding 17 years, only a few important technical improvements were reported to have significantly enhanced survival..$^{3,5-8}$ In fact, during the first 3 years in which cyclosporine was used, mortality related to a difficult intraoperative course remained a disturbing problem. For the most part, these difficulties centered around the anhepatic phase and repeatedly underscored the need for an effective method of venous bypass. The need for the development of new methodology was clearly demonstrated by the severe penalty imposed by the requirement for systemic heparinization during a trial of venous bypass using conventional

Presented at the 104th Annual Meeting of the American Surgical Association, Toronto, Canada, April 25-27, 1984.

Supported by research grants from the Veterans Administration and by project Grant AM-29961 from the National Institutes of Health.

Reprint requests: Byers W. Shaw, Jr., M.D., Department of Surgery, 3601 Fifth Avenue, Room 103 Falk Clinic, Pittsburgh, PA 15213.

Submitted for publication: April 30, 1984.
From the Departments of Surgery ${ }^{*}$ and Anesthesiology, $\dagger$ University Health Center of Pittsburgh, Pittsburgh, Pennsylvania

techniques in 12 patients during the summer of 1982 . The development in the laboratory of a heparin-less bypass system was reported by Denmark et al. ${ }^{9}$ and the initial clinical trial using these techniques presented by Griffith et al. ${ }^{10}$ The effectiveness of this method of venous bypass is the subject of the current study.

\section{Methods}

Between February 15, 1983 and March 22, 1984, a total of 57 adults were treated with orthotopic hepatic transplantation at the University of Pittsburgh using venous bypass without the use of systemic anticoagulation. The technique used is essentially that described by Griffith with only minor changes. In particular, the use of a 9-mm Gott (Argyle Division, Sherwood Medical, St. Louis, MO) shunt for cannulation of the portal vein and a $7-\mathrm{mm}$ shunt for the axillary vein has proven to be a more satisfactory alternative to the reverse situation described in the previous paper. ${ }^{10}$ The femoral vein is cannulated with a $7-\mathrm{mm}$ Gott shunt via a cut-down on the saphenous vein.

The femoral and portal vein cannulae come together at a metal Y-connector, which is in turn attached to $3 / 8$-inch polyvinyl chloride tubing (Tygon, Norton Industrial Plastics, Akron, $\mathrm{OH}$ ), which leads to a conical, centripetal force pump head (Bio-Medicus, Inc., Minnetonka, MN). The return flow is to the axillary vein. The system is a completely closed one that does not require a reservoir in the circuit. An electromagnetic flow meter (Bio-Medicus, Inc., Minnetonka, MN) is attached to the outflow of the pump head. Flows are maintained at $1000 \mathrm{ml} / \mathrm{min}$ or more, a rate that was defined in the laboratory as that below which formation of clots and platelet aggregates were more likely to occur. Once bypass flow has been established at a satisfactory rate, the vena cava below and above the 
native liver is clamped and the liver excised. Hemostasis in the liver bed can then be obtained, if necessary. The portal venous and lower caval systems are decompressed so that, in general, venous hypertension does not exacerbate the bleeding at this point.

The revascularization of the new liver then occurs in a routine manner. ${ }^{3}$ The usual sequence involves sewing the upper vena cava anastomosis followed by the lower caval anastomosis. The liver is then flushed out with 300 to $500 \mathrm{ml}$ of cold saline via the portal vein cannula. This step flushes the preservation fluid, high in potassium, out of the liver. It also fills and evacuates air from the vena cava. The patient is placed in a Trendelenberg position and the fluid allowed to escape through the anterior part of the lower caval anastomosis. Whether the portal vein or the arterial anastomosis is completed next is dependent upon a number of variables. In general, 60 to 80 minutes are allowed for the anastomoses before some flow is returned to the liver. In those situations where clamping the portal vein side of the bypass circuit (in order to perform the portal vein anastomosis) results in dropoff of the flow below 1000 $\mathrm{ml} / \mathrm{min}$, the bypass should be discontinued to minimize the chance of thrombus formation. If the arterial anastomosis has been completed by this time, the arterial and caval clamps can be released prior to decannulating the portal vein and coming off bypass. The proper choice for sequencing these steps must be determined by the surgeon for each situation.

\section{Intraoperative Monitoring}

Cardiopulmonary data were obtained using a multiple lumen pulmonary artery catheter. In the subset of patients for whom complete profiles were obtained, a four-lumen catheter employing an oximeter at the distal tip (Oximetrix, Inc., Mountain View, CA) was employed. Complete cardiopulmonary profiles were obtained prior to the induction of anesthesia, after anesthesia had been established but before significant fluid losses had occurred, just before initiating the bypass, during the bypass, and shortly after revascularization of the liver. Oxygen consumption was calculated using the Fick equation. Coagulation data were obtained routinely on all patients using a thromboelastogram.

\section{Renal Function}

The mean serum creatinine of all patients was determined immediately prior to undergoing liver transplantation and then after surgery. Comparisons were made between the preoperative values and the highest postoperative value within 72 hours of transplantation. The means were compared using the paired and unpaired Student's t-tests. The number of patients in the bypass and non-bypass groups who were not on dialysis prior to surgery but who required dialysis within the first 7 days of transplantation were determined and compared using the chi square test. Patients with preoperative renal failure or preoperative requirements for dialysis were eliminated from this latter comparison. A subset of 30 consecutive patients were monitored for urine output during surgery.

\section{Blood Use}

Figures regarding the number of units of blood components used during transplantation operations were kept by the Central Blood Bank of Pittsburgh. Mean blood use was compared using the Student's unpaired t-test and the median values by the rank-sum test.

\section{Mortality and Survival}

Life-table analysis was used to determine survival of the various groups and these values compared by the method of Greenwood ${ }^{11}$ using the standard errors of the survival possibilities for each interval. Minimum followup on all patients was 35 days. A total of 63 and 57 patients in the non-bypass and bypass groups, respectively, were used for survival calculations.

\section{Heparinized Bypass from June 15-September 6, 1982}

Twelve patients, nine of whom were adults, underwent liver transplantation using a conventional bypass system that necessitated systemic anticoagulation with heparin. These are the subject of a brief comparison with the current system.

\section{Results}

From March 9, 1980 to March 22, 1984, a total of 129 adult patients, 12 at the University of Colorado and 117 at the University of Pittsburgh, underwent orthotopic hepatic transplantation. Sixty-three of these patients were treated without the use of any venous bypass technique, nine with a bypass technique utilizing systemic anticoagulation, and 57 utilizing venous bypass without systemic anticoagulation. The indications for transplantation are shown in Table 1.

\section{Cardiopulmonary Data}

Flow in the bypass system ranged from 1 to 13 liters per minute, with a mean of $2.77( \pm 0.827) \mathrm{L} / \mathrm{min}$. Average bypass time was $91.2( \pm 19.7)$ minutes. Complete cardiopulmonary data were obtained in 28 consecutive cases between March 30 and August 16, 1983. These data are presented in Table 2 . The pre-bypass values are the means $( \pm \mathrm{SD})$ of those obtained after induction of 
TABLE 1. Indications for Liver Transplantation

\begin{tabular}{lcc}
\hline & $\begin{array}{c}\text { No } \\
\text { Bypass }\end{array}$ & Bypass \\
\hline Postnecrotic cirrhosis & 25 & 17 \\
Primary biliary cirrhosis & 12 & 16 \\
Sclerosing cholangitis & 6 & 10 \\
Malignancy & 6 & 5 \\
Budd-Chiari syndrome & 4 & 0 \\
Secondary biliary cirrhosis & 4 & 1 \\
Alpha-1-antitrypsin deficiency & 4 & 1 \\
Wilson's disease & 0 & 4 \\
Miscellaneous & 2 & 3 \\
Total & 63 & 57 \\
\hline
\end{tabular}

anesthesia but before devascularization of the native liver. The bypass data are the means $( \pm \mathrm{SD})$ of the data obtained during the actual anhepatic state while patients were undergoing venous bypass. These data show that the oxygen consumption $\left(\mathrm{VO}_{2} / \mathrm{M}_{2}\right)$ fell secondary to a decrease in temperature $(\mathrm{T})$ and removal of the liver. Consequently, cardiac index (CI) fell without an increase in arterial-venous oxygen content difference $\left(\mathrm{a}-\mathrm{vDO}_{2}\right)$, reflecting adequate tissue oxygenation. In addition, sys-

TABLE 2. Cardiopulmonary Profiles

\begin{tabular}{|c|c|c|c|c|c|}
\hline \multirow[b]{2}{*}{ Variable } & \multicolumn{2}{|c|}{ Pre-bypass } & \multicolumn{2}{|c|}{ Bypass } & \multirow[b]{2}{*}{$\mathbf{P}$} \\
\hline & Mean & SD & Mean & SD & \\
\hline $\mathrm{T}\left({ }^{\circ} \mathrm{C}\right)$ & 34.9 & .98 & 33.8 & 1.16 & 0.0002 \\
\hline HR (bpm) & 85.6 & 14.3 & 84.1 & 14.2 & \\
\hline MAP $(\mathrm{mmHg})$ & 75 & 17.1 & 83 & 17.6 & \\
\hline PAO (torr) & 12.0 & 4.2 & 10.5 & 3.3 & \\
\hline $\mathrm{CVP}(\mathrm{mmHg})$ & 9.9 & 4.4 & 9.2 & 4.9 & \\
\hline $\mathrm{pCO}_{2}$ (torr) & 33.3 & 5.2 & 29.9 & 4.8 & 0.0125 \\
\hline $\mathrm{pO}_{2}$ (torr) & 380 & 92.4 & 398 & 91.6 & \\
\hline $\mathrm{SaO}_{2}$ & 0.9854 & 0.0915 & 0.9896 & 0.0160 & \\
\hline $\mathrm{PvO}_{2}$ (torr) & 65.5 & 16.3 & 70.8 & 21.5 & \\
\hline $\mathrm{SvO}_{2}$ (torr) & 0.904 & 0.0598 & 0.927 & 0.0496 & \\
\hline $\operatorname{Hgb}(\mathrm{g} / \mathrm{dl})$ & 9.62 & 1.16 & 10.2 & 1.42 & \\
\hline $\mathrm{pHa}$ & 7.42 & 0.07 & 7.40 & 0.08 & \\
\hline $\mathrm{CI}\left(\mathrm{L} / \mathrm{min} \cdot \mathrm{m}^{2}\right)$ & 4.37 & 1.44 & 3.44 & 1.09 & 0.0079 \\
\hline SI & 51.7 & 15.9 & 41.4 & 13.6 & 0.0121 \\
\hline RVSWI & 5.11 & 3.21 & 3.52 & 3.17 & \\
\hline LVSWI & 43.4 & 14.3 & 39.7 & 11.4 & \\
\hline SVRI & 443.7 & 233 & 660 & 366 & 0.0109 \\
\hline PVRI & 34.3 & 23.9 & 44.1 & 39.1 & \\
\hline $\mathrm{a}-\mathrm{vDO}_{2}$ & 2.04 & .81 & 1.87 & .59 & \\
\hline $\mathrm{VO}_{2} / \mathrm{m}^{2}$ & 83.0 & 24.7 & 61.7 & 20.5 & 0.0009 \\
\hline $\mathrm{O}_{2}$ transport & 1087 & 391 & 917 & 342 & \\
\hline
\end{tabular}

HR-heart rate; MAP-mean arterial pressure; $\mathrm{PAO}$-pulmonary arterial wedge pressure; $\mathrm{CVP}$-central venous pressure; $\mathrm{pCO}_{2}$-partial pressure carbon dioxide; $\mathrm{pO}_{2}$-partial pressure oxygen; $\mathrm{SaO}_{2}$-arterial oxygen saturation; $\mathrm{PvO}_{2}$-mixed venous oxygen pressure; $\mathrm{SvO}_{2}$-oxygen saturation pulmonary artery; $\mathrm{Hgb}$-hemoglobin; $\mathrm{pHa}$-arterial $\mathrm{pH}$; CI-cardiac index; SI-saturation index; RVSWI-right ventricular stroke work index; LVSWI-left ventricular stroke work index; SVRI-systemic vascular resistance; PVRI-pulmonary vascular resistance; a-vDO ${ }_{2}$-arterial-venous oxygen content difference; $\mathrm{VO}_{2} / \mathrm{m}^{2}$-oxygen consumption.
TABLE 3. Comparisons of Postoperative Renal Function

\begin{tabular}{lccc}
\hline & $\begin{array}{c}\text { No Bypass } \\
(\mathrm{N}=38)\end{array}$ & $\begin{array}{c}\text { Bypass } \\
(\mathrm{N}=48)\end{array}$ & $\mathrm{p}$ \\
\hline $\begin{array}{l}\text { Preoperative mean } \\
\text { serum creatinine }\end{array}$ & $1.65 \pm 1.85$ & $1.23 \pm 1.43$ & \\
& $\mathrm{p}<0.005$ & $\mathrm{p}<0.05$ & \\
$\begin{array}{l}\text { Postoperative mean } \\
\text { serum creatinine* }\end{array}$ & $3.00 \pm 2.70$ & $1.51 \pm 1.27$ & \\
$\begin{array}{l}\text { Mean change } \\
\begin{array}{l}\text { Patients requiring } \\
\text { dialysis during } \\
\text { first postoperative }\end{array}\end{array}$ & & & \\
week & 6 & $0.35 \pm 0.90$ & $\mathrm{p}<0.001$ \\
\hline & & 0 & $\mathrm{p}<0.01$ \\
\hline * Maximum value in first 3 postoperative days. &
\end{tabular}

temic vascular resistance (SVRI) fell significantly while mean arterial pressure (MAP), central venous pressure (CVP), and pulmonary arterial wedge pressures (PAO) did not change.

\section{Renal Function}

Table 3 reveals that renal function changed to a significant degree in both the patients with bypass and those without. Of note is that the increase in creatinine in the non-bypass group $(+1.29 \pm 1.95 \mathrm{mg} / \mathrm{dl})$ is significantly greater $(p<0.001)$ than that seen in the bypass group $(+0.35 \pm 0.90 \mathrm{mg} / \mathrm{dl})$. Complete anuria or marked oliguria was not an infrequent occurrence during the anhepatic phase in the previous experience with liver transplantation. ${ }^{3}$ Urine output during the anhepatic phase is maintained quite well in patients on bypass, with a mean urine flow of $187( \pm 249) \mathrm{ml} /$ hour (range $0-1360 \mathrm{ml} /$ hour). Complete anuria was experienced in only one patient in the bypass group. In addition, marked hematuria, a postoperative occurrence in $10 \%$ to $15 \%$ of non-bypass adults, has been absent in the bypass group.

\section{Blood Use}

Data were compared for the total blood use during the transplant operation of 36 patients using venous bypass and a total of 43 without bypass. These data are presented in Table 4. The range in blood use of the non-bypass group was 3 to 251 units of packed red blood cells (PRBC) and was 5 to 157 units PRBC for

TABLE 4. Packed Red Blood Cell Requirement (Units)

\begin{tabular}{llll}
\hline & $\begin{array}{c}\text { No Bypass } \\
(\mathrm{N}=43)\end{array}$ & \multicolumn{1}{c}{$\begin{array}{c}\text { Bypass } \\
(\mathrm{N}=36)\end{array}$} & \multicolumn{1}{c}{$\mathrm{p}$} \\
\hline Range & $3-251$ & $5-157$ & \\
Median & 27 & 16 & $\mathrm{p}<0.05$ \\
Mean & $32.7 \pm 25.1$ & $18.9 \pm 8.0$ & $\mathrm{p}<0.01$ \\
\hline
\end{tabular}


the bypass group. The median blood use was 27 for the non-bypass group versus 16 for the bypass group ( $p$ $<0.05$ ). Mean blood use was calculated by eliminating 10 cases from each group. The five lowest and five highest numbers were withdrawn from the comparison because of the wide standard deviations, which did not allow for a representative comparison. The mean loss in the non-bypass group (32.7 \pm 25.1 units PRBC) was higher $(p<0.01)$ than in the bypass group $(18.9 \pm 8.0$ units PRBC). An examination of Table 5 reveals that the mean blood loss with the heparinized bypass system was $53.1 \pm 33$ units PRBC with a range of 10 to 94 units, significantly higher than the non-heparin bypass group $(\mathrm{p}<0.001)$ or the non-bypass group $(\mathrm{p}<0.05)$.

\section{Hospital Stay}

The number of days that patients remained in the hospital from the date of transplantation to the date of discharge are compared for the two groups in Table 6 . The mean length of stay for the non-bypass group was $56.4( \pm 35.1)$ days versus $51.1( \pm 28.9)$ days for those bypassed $(p>0.50)$. If all patients whose prolonged hospital stay was secondary to retransplantation were eliminated, the length of stay is still not different between these groups $(p>0.05)$.

\section{Bypass and Retransplantation}

The requirements for retransplantation are similar between the bypass and non-bypass groups, with 14 patients in the former and 12 in the latter group requiring retransplantation. The survival following retransplantation is not significantly different at either 1 month or 3 months after surgery.

\section{Mortality and Survival}

The actuarial survival curves for the non-bypass and bypass groups are shown in Figure 1. All patients in each group were followed for a minimum of 30 days after surgery and included 57 bypass and 63 non-bypass patients. Survival at 30 days was $91.1 \%$ for the bypass group compared to $73 \%$ for the non-bypass group (p $<0.004$ ). At 90 days, however, survival in the bypass group $(73.2 \%)$ was not significantly different from that in the group without bypass $(68.3 \%)(p>0.05)$. Six of the patients in whom bypass was not used died on the operating table. The one operative death occurring in the bypass group was the result of an irreparable injury to the donor liver. That patient experienced no cardiodynamic instability during the hepatic revascularization. Table 5 reveals that three of nine patients bypassed using anticoagulation died in the operating room, and a fourth expired before 30 days. Only two of the nine
TABLE 5. Experience with Venous Bypass using Systemic Anticoagulation, June 25, 1982 to September 6, 1982 (Nine Adult Patients Undergoing 11 Operations)

\begin{tabular}{ll}
\hline Operative deaths & $3 / 9(33 \%)$ \\
Mean blood loss (units PRBC) $\dagger$ & $53.1 \pm 33.0^{*} \pm \mathrm{SD}$ \\
Range & $10-94$ \\
30-day survival & $5 / 9(55.6 \%)$ \\
90-day survival & $2 / 9(22.2 \%) \ddagger$ \\
\hline
\end{tabular}

* $\mathrm{p}<0.05$ compared to no bypass; $\mathrm{p}<0.01$ compared to nonheparinized bypass.

† PRBC-packed red blood cells.

$¥$ Each living, 22 months after surgery.

patients survived beyond 90 days and both were living 22 months after surgery at the conclusion of this study.

An examination of the causes of death in both groups reveals that they are quite similar. Sepsis, accompanied by multiple organ failure and, in particular, liver failure, was universal. In an attempt to understand why the significant difference in survival at 30 days was no longer present by 90 days, patients were classified into three groups. Status 1 patients are stable, relatively low-risk candidates, including those who are primarily outpatient care-dependent with only infrequent hospitalization. Nutritional status is good to excellent. A history of significant esophageal variceal bleeding but with rapid recovery would not exclude a patient from this group. Status 2 patients are those who require frequent hospitalization, who have advanced cirrhosis with moderate to severe ascites, occasional episodes of grade 3 to 4 encephalopathy, recurrent episodes of variceal bleeding with attendant worsening of encephalopathy, and those whose life-style has been significantly altered by their disease. A history of previous major abdominal surgery, which would increase a candidate's intraoperative risk, would lead to a change in status from category 1 to 2 . Status 3 patients were the very high-risk group. The criteria for which patients would be placed into this group are either metabolic or technical. All of the metabolic group patients require hospitalization, most in the intensive care unit. All have frequent bouts of grade 3 to 4 encephalopathy. Malnutrition is severely advanced; ascites and hypoalbuminemia are extreme. Some patients with acute hepatic decompensation secondary to toxic agents were placed under this category by virtue of their emergent situation. In the current

TABLE 6. Postoperative Hospital Stay

(Patients Discharged in Pittsburgh)

\begin{tabular}{llll}
\hline & $\begin{array}{c}\text { No Bypass } \\
(\mathrm{N}=30)\end{array}$ & \multicolumn{1}{c}{$\begin{array}{c}\text { Bypass } \\
(\mathrm{N}=37)\end{array}$} & \\
\hline Range & $16-145$ days & $21-165$ days & \\
Median & 51 days & 42 days & $\mathrm{p}>0.05$ \\
Mean & $56.4 \pm 35.1$ & $51.1 \pm 28.9$ & $\mathrm{p}>0.50$ \\
\hline
\end{tabular}




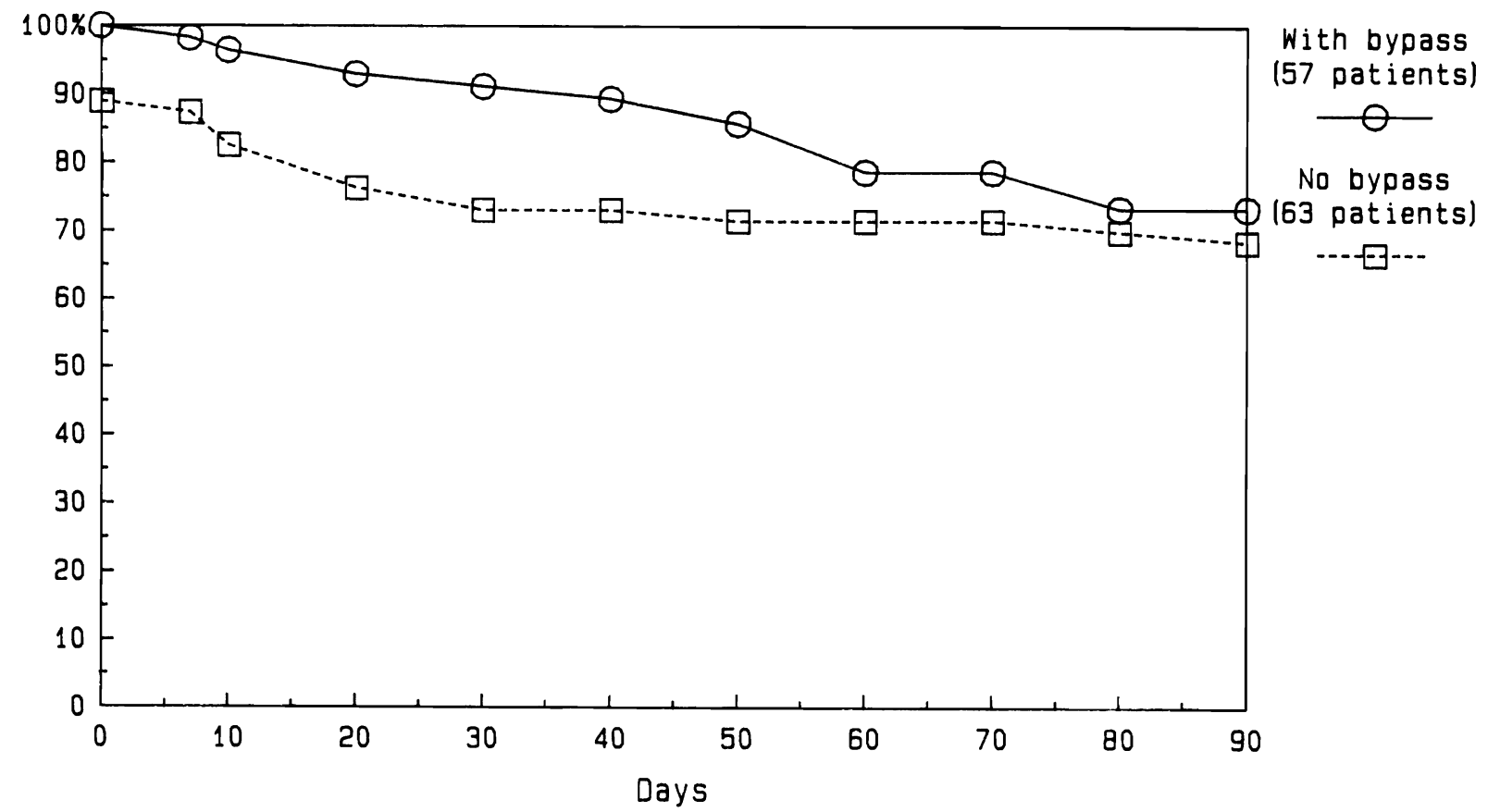

$p<0.01$ at 7 days

$p<0.01$ at 30 days

FIG. 1. Ninety-day actuarial survival for liver transplants performed with and without venous bypass.

study, nine of the 26 Status 3 patients (four in the nonbypass, five in the bypass group) were in stage 4 coma in an intensive care unit setting with severe renal dysfunction and requiring ventillatory support. Technical considerations that would require a Status 3 classification include a previous portacaval shunt, thrombosed portal vein, or multiple previous abdominal surgeries involving the liver or bile ducts. Four patients in the non-bypass and two in the bypass group were so classified.

A breakdown of the survival curves based on this assignment of status is depicted in Figures 2, 3, and 4. In Status 1 patients, eight of nine non-bypass and all six bypass patients remain alive at the end of the study. Among 41 Status 2 patients without bypass, 30-day and 90 -day survival is $88 \%$ and $76 \%$, respectively, compared to $97.2 \%$ and $85.2 \%$ for the same intervals among 38 Status 2 patients treated with bypass. Thirteen patients were classified as Status 3 in both the non-bypass and bypass groups. Survival at 30 days was $31 \%$ for the nonbypass group compared to $61.5 \%$ of the bypass group $(p<0.01)$. However, mortality in the bypass group between 30 and 90 days was significantly higher ( $p$ $<0.05$ ) than in the non-bypass group, so that survival by 90 days was $31 \%$ and nine per cent in the nonbypass and bypass groups, respectively ( $p<0.05$ ). Among the four patients classified as Status 3 in the non-bypass group because of technical considerations, three were operative deaths and the fourth died in less than 48 hours after surgery. Both of the technical Status 3 bypass patients are alive 2 and 6 months after surgery.

\section{Discussion}

Despite the landmark improvements in survival rates among liver transplant recipients provided by the introduction of cyclosporine, ${ }^{1-4}$ early mortality and morbidity related to a difficult intraoperative course remained a significant problem. Approximately $50 \%$ of all patients who died within 1 year following transplantation were lost by the end of the first 30 days. In addition, operative mortality among the first 63 adult patients treated with cyclosporine was $9.5 \%$.

\section{Historical Background}

Physiologically and sometimes technically, the most difficult period of the actual transplant operation is the anhepatic phase, when the native liver has been removed. Cross-clamping the portal vein and the abdominal portion of the inferior vena cava causes several problems. The first results from the loss of return to the central venous system of the large volume of caval flow from the abdomen. The second stems from the hypertension that develops in the obstructed portal and systemic venous beds. The third occurs at the time of liver 
Percent survival

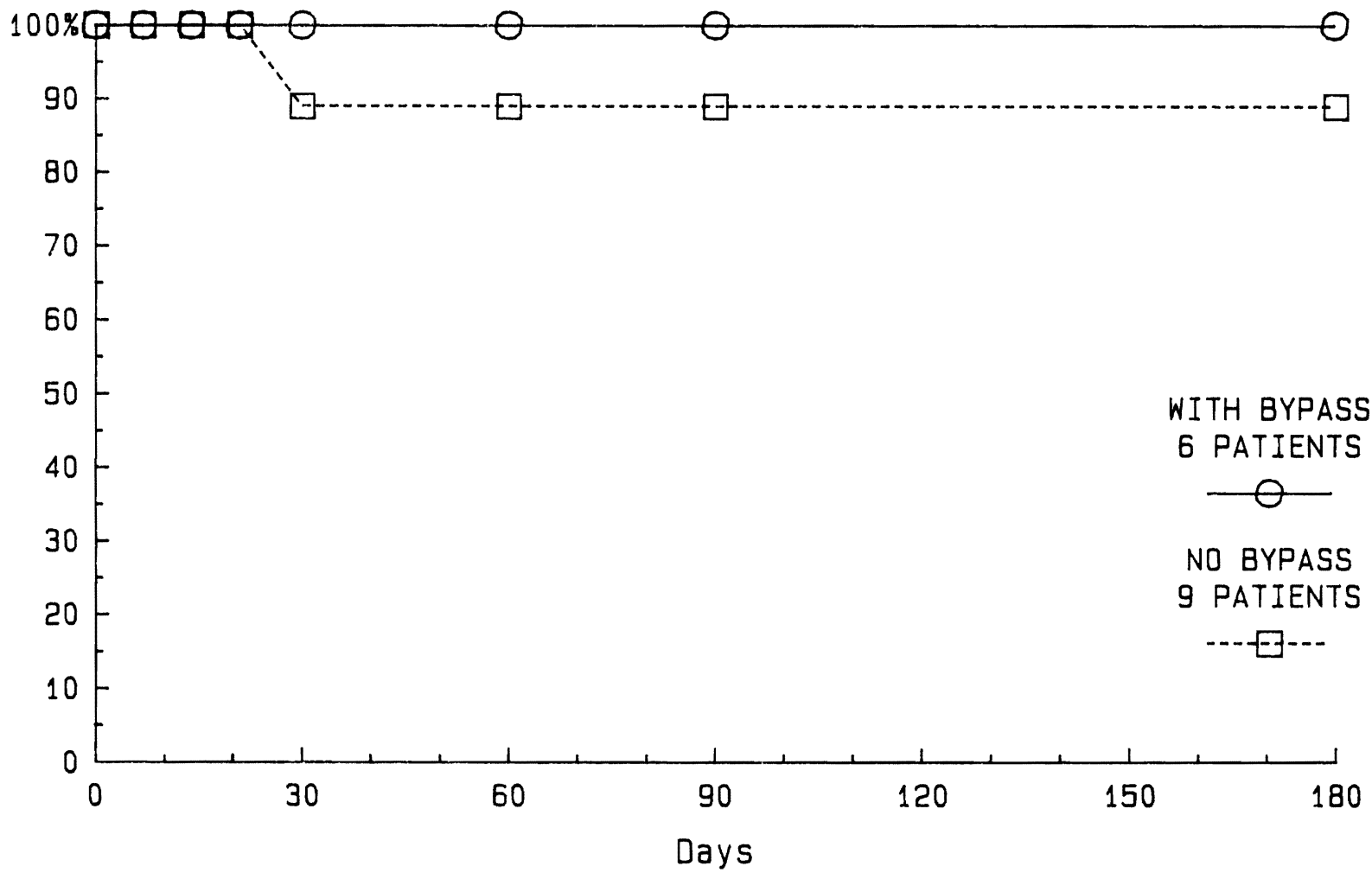

FIG. 2. Actuarial survival of Status 1 patients with and without venous bypass.

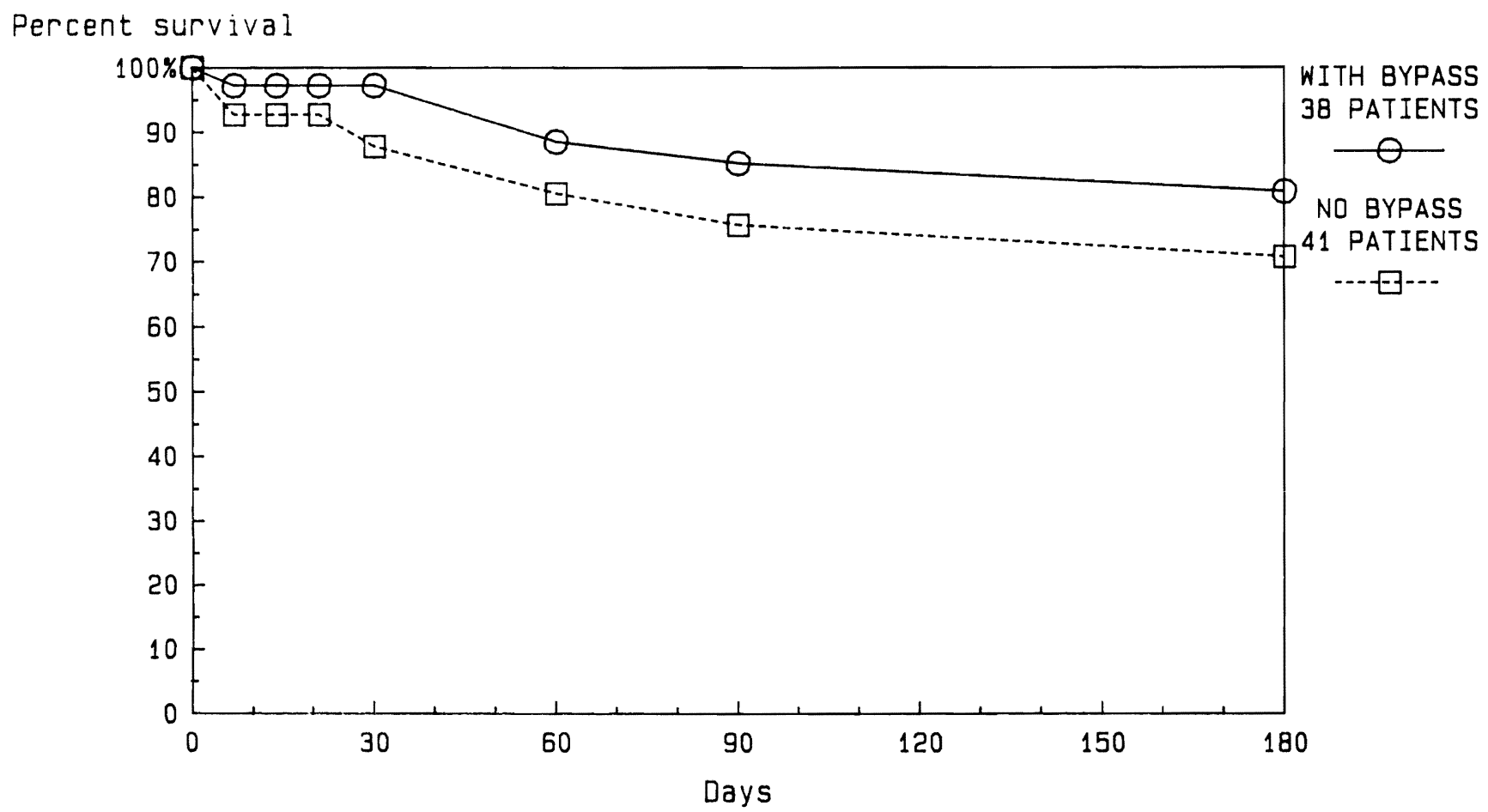

FIG. 3. Actuarial survival of Status 2 patients with and without venous bypass. 


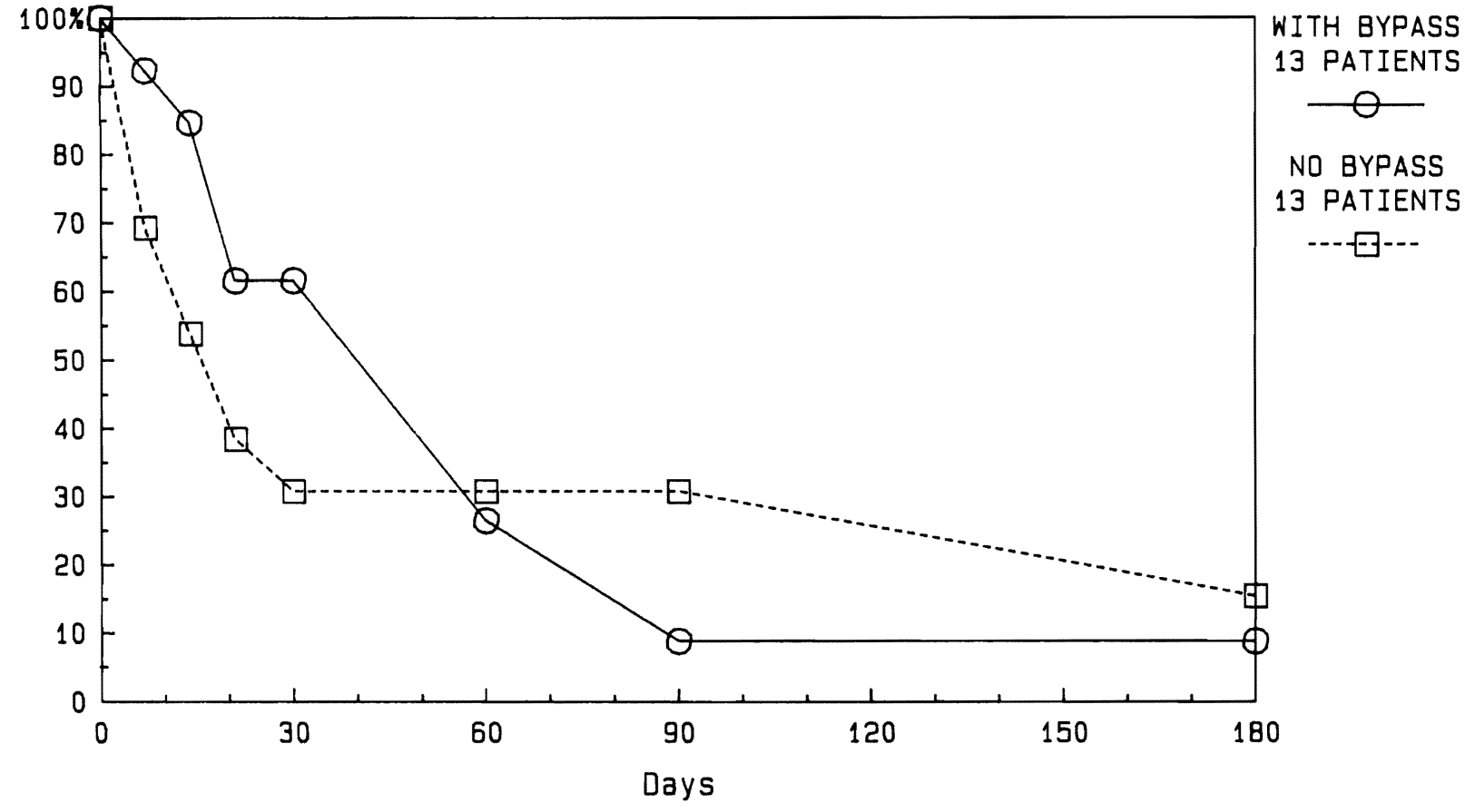

$p<0.01$ at 30 days

$p<0.05$ at 90 days

FIG. 4. Actuarial survival of Status 3 patients with and without venous bypass.

revascularization when stagnant blood from the obstructed venous beds, sometimes rich in acid and potassium, is suddenly returned into the systemic circulation.

Previous studies revealed that the typical response to the anhepatic phase is a $50 \%$ reduction in cardiac output accompanied by a marked increase in systemic vascular resistance. ${ }^{12}$ More recent experience has shown that the response can be quite variable. In young, otherwise healthy individuals it is similar to what occurs in severe acute hypovolemia. Although arterial blood pressure is fairly well maintained, cardiac output is reduced to as much as one-fifth of the preocclusion levels while systemic vascular resistance increases three to four fold. Patients with preexisting cardiac dysfunction, or older patients, do not tolerate the loss in central venous volume and marked increase in vascular resistance well and can develop cardiac failure, marked hypotension, cardiac arrhythmias, and even cardiac arrest. Even patients with more resilient cardiac function will sometimes require the infusion of large volumes of fluid (or blood products) into the central venous system in order to compensate for the marked fall in preload. The penalty for this is severe fluid overload at the time of liver revascularization when normal venous return is restored. ${ }^{3}$

The occlusion of portal venous outflow is tolerated to quite variable degrees as well. Clamping the portal vein in the normal dog results in the death of the animal within 20 to 30 minutes. ${ }^{12,13}$ Cirrhotic dogs, however, can tolerate portal vein clamping for over 1 hour. ${ }^{14}$ Clamping the portal vein in normal man causes fewer problems, either because of a more extensive collateral network or because of the normal lack of bacterial flora in human portal blood. ${ }^{15,16}$ Even so, the presence of portal hypertension and extensive collateral circulation in humans with cirrhosis probably provides an advantage similar to that in the canine cirrhosis model. ${ }^{3}$ This has been particularly evident when long periods (greater than 1 hour) of portal occlusion have been necessary in patients without portal hypertension, such as those with primary malignancies. The degree of gut swelling and petechial hemorrhage in the bowel wall has been much more severe than that seen in cirrhotics. Frank gastrointestinal hemorrhage has not been an infrequent occurrence in this setting.

In the normal dog model, various methods are used to keep portal occlusion times as brief as possible. These include the classic method of end-to-side portacaval shunt combined with a femoral-to-jugular venous bypass cannula 12,13 or the use of the "cuff" technique for vascular anastomoses originally used by $\mathrm{Kamada}^{17}$ in rats and employed for the normal dog model by Monden. ${ }^{18}$ 
The original human trials at Denver involved the use of venous bypasses in anticipation of problems similar to those seen in dogs. ${ }^{19}$ But the inordinate incidence of embolic phenomena accompanying the use of passive shunts led to their abandonment when certainty evolved that humans tolerated the anhepatic phase without venous decompression much better than dogs. ${ }^{15,16}$ Calne has selectively used partial cardiopulmonary bypass in an attempt to support patients during the anhepatic phase, with varying degrees of success. ${ }^{20}$

A trial of venous bypass using a conventional cardiac bypass apparatus was undertaken in Pittsburgh in the summer of 1982. Although physiologic advantages during the anhepatic phase were quite evident, these were outweighed by the severe penalty imposed by the need for anticoagulation. This is graphically demonstrated in Table 5. Attempts at minimizing the use of heparin provided no improvements and the technique was soon abandoned.

But the need for some sort of bypass technique remained all too evident by the recurring nightmares of the anhepatic phase in a number of patients. Hence, a trial of a method that would not require the use of systemic anticoagulation was undertaken in the laboratory using the normal dog model. The success of these experiments, as mentioned earlier, was reported by Denmark $^{9}$ and the initial clinical experience presented by Griffith. ${ }^{10}$

\section{Hemodynamic Advantages}

The data presented in the current study demonstrate the degree to which normal physiology is restored by the use of a venous bypass system. Cardiac filling pressures (as measured by a pulmonary artery catheter) are supported, and although the cardiac index falls, it does so to a much lesser degree than it does without bypass and apparently as an appropriate response to decreased demand. This latter contention is supported by the observation that at the same time that cardiac output has fallen, oxygen consumption also decreases while the mixed venous oxygen content does not change significantly. One possible explanation for this is the removal of the liver, a large metabolic machine, from the system. But in addition, the patient's core temperature falls significantly, further lowering metabolic demand. This fall in temperature has been reported before. ${ }^{21}$ It was attributed to a variety of causes in the previous report, including long operating times, the presence of the cold $\left(4-10^{\circ} \mathrm{C}\right)$ donor liver in the abdomen while the vascular anastomoses were completed, and the revascularization of the donor liver when cold preservation solution is flushed out of the liver and into the systemic circulation by the restored blood flow. The technique of venous bypass used currently is a closed system without a heat exchanger in the circuit. Additional cooling of blood undoubtedly occurs as it passes through the bypass circuit. Patient core temperature falls continuously during the bypass phase and reaches a nadir just after liver revascularization.

The high volume of blood returned to the heart from the venous beds that otherwise would be obstructed is further evidenced by the high flow rates obtained in the bypass circuits. The mean flow for all patients of 2.77 $( \pm 0.827) \mathrm{L} / \mathrm{min}$ represents $55 \%$ of the mean cardiac output obtained for these patients during the bypass phase.

\section{Renal Function}

The smaller increase in serum creatinine level and the virtual elimination of the requirement for hemodialysis during the early recovery phase in the bypass group is encouraging. Previous difficulties, evident in the current study by the mean postoperative serum creatinine in the non-bypass group of $3.0( \pm 2.7) \mathrm{mg} / \mathrm{dl}$ and by the requirement among six patients (without overt renal dysfunction before surgery) for hemodialysis during the first week following transplantation, are undoubtedly related to renal damage occurring primarily during the anhepatic phase when the suprarenal vena cava is completely occluded.

\section{Blood Use}

The lower blood use documented since routine venous bypass was instituted is explained by several factors. The most important results from the complete lack of venous hypertension in the systemic and splanchnic beds during the anhepatic phase. Without bypass, this hypertension continues to increase and hemorrhage can accelerate markedly during the anhepatic phase. The bypass also allows for a certain period of time (15-60 minutes) of meticulous effort at hemostasis in the hepatic bed after the liver is out of the way.

\section{Length of Postoperative Recovery}

The use of bypass had no effect on the length of hospital stay. This is true even if one eliminates from consideration all patients whose recovery was complicated by the necessity for a second or third transplant. A bias may be present in these figures since the routine monitoring of daily cyclosporine blood levels was instituted after the introduction of venous bypass for all adult recipients. These blood levels demonstrated surprisingly variable cyclosporine absorption, which necessitated prolonged hospital stays for a number of patients who might otherwise have been discharged earlier in the pre-bypass era. 


\section{Mortality and Survival}

An examination of Figure 1 reveals that although intraoperative mortality and the postoperative mortality up through the first 30 days is markedly less in the bypass group, by 90 days this difference is no longer significant. The reason for this apparent paradox is revealed by Figures 2, 3, and 4. Four of 13 patients in the high-risk group (Status 3) who were not bypassed died in the operating room in contrast to no operative deaths in the bypass Status 3 group. At 30 days, the improved survival continued but was overshadowed by a markedly increased mortality in the bypass group during the next 60 days when compared to the nonbypass group. Seven of these 13 bypass patients required retransplantation, two in whom rejection followed periods of satisfactory liver function, the other five without every obtaining satisfactory hepatic graft function. Two of these patients died before 30 days, the other five between 30 and 90 days. In the non-bypass group, two patients required retransplantation, both of whom subsequently died. More importantly, only two of the bypass patients were classified Status 3 because of extreme technical considerations and these are the only two survivors from this category. In contrast, four of the 13 non-bypass Status 3 patients were so categorized for technical concerns. Three died during surgery and the fourth 2 days later.

The causes of death among those in both groups who survived beyond the first 2 weeks after surgery are virtually indistinguishable. All had severe hepatic dysfunction and developed sepsis with subsequent multiple organ failure. Overall, this is an extremely high-risk group in whom the application of venous bypass results in improvements in early survival but appears to have little impact on the long-term results. An extremely important exception to this conclusion must be made in the case of those patients determined to be high risk for technical reasons. Both surviving patients in the bypass group would almost certainly have been operative mortalities without the use of bypass. In fact, in the prebypass era, one of these patients would have been excluded from candidacy for liver transplantation by virtue of having a known portal vein thrombosis.

\section{Complications}

No pulmonary emboli or deep venous thromboses related to the bypass procedure have occurred. Wound seromas or hematomas in the groin or axilla have developed in six patients. All of these collections resolved spontaneously, two following drainage. During surgery, no changes in blood coagulation profiles attributable to bypass have been seen.
Recent experience reveals that patients with acute Budd-Chiari syndrome are probably not candidates for venous bypass. In two recent cases, attempts at thrombectomy of the clotted portal and vena caval systems followed by establishment of bypass resulted in suboptimal flows in the bypass circuit. In addition, the risk for embolizing preformed thrombus material was recognized to be quite high. Attempts at bypass were abandoned in both of these cases and the anhepatic phase proceeded without incidence.

\section{Other Considerations}

Some of the most important advantages of the venous bypass, however, are not demonstrable by the strict analysis of physiologic and survival data. Many situations arise in which portal and caval venous occlusion times must be extended beyond the normal 60 to 90 minutes usually felt acceptable without bypass techniques. This includes any patient in whom the normal, careful, meticulous dissection during the recipient hepatectomy is impossible, and removal of the liver can be accomplished safely only by immediate and complete devascularization of the organ, followed by rapid resection. Hemostasis in the bed is then obtained during the anhepatic phase, and may require an hour or more of intense effort which, if accompanied by increasing portal and caval venous hypertension, may prove fruitless, even dangerous. The bypass system in this situation allows for a period of careful and deliberate hemostasis while keeping the venous beds decompressed and maintaining central venous pressures. It also allows time for careful preparation of vessels for anastomoses, including dissecting out a usable recipient hepatic artery and portal vein if this were not possible before complete hepatectomy. Finally, the bypass removes a great deal of pressure from the surgeon performing the vascular anastomoses since the onus of completing them quickly and yet accurately is somewhat lessened. This offers particular advantages in a training situation.

\section{Future Outlook}

In general, pediatric patients have fared much better than have adults during the anhepatic phase of orthotopic liver grafting. Nevertheless, a method of venous bypass for the small patient would offer distinct advantages in a number of high-risk situations. Application of the apparatus currently in use is hindered by the lower limit of bypass flow $(1000 \mathrm{ml} / \mathrm{min})$ required to eliminate the possibility of thrombus formation. In certain situations, the disadvantages of systemic heparinization of the recipient may be overshadowed by the life-sustaining support of a venous bypass. In addition, the laboratory experience that defined the safety of the lower limit of 
bypass flow was all obtained without the use of heparinbonded cannulae, tubing, or pump heads. Work is in progress that may redefine the lower limit of safe bypass flow and thus make venous bypass available in pediatric patients.

Last, although the final impact of venous bypass alone has yet to be determined, its routine use has significantly lowered the early mortality which, in the past, has often been associated with a difficult intraoperative course. The fact that its overall impact is not greater underscores the continuing need for better immunosuppression and better definition of the overwhelming risk factors in recipients.

\section{References}

1. Starzl TE, Klintmalm GBG, Weil R III, et al. Liver transplantation with use of cyclosporin-A and prednisone. N Engl J Med 1981; 305:266-269.

2. Calne RY, Williams $R$, Lindop $M$, et al. Improved survival after orthotopic liver grafting. Br Med J 1981; 283:115-118.

3. Starzl TE, Iwatsuki S, Van Thiel DH, et al. Evolution of liver transplantation. Hepatology 1982; 2:614-636.

4. Malatack JJ, Zitelli BJ, Gartner JC et al. Pediatric liver transplantation under therapy with cyclosporin-A and steroids. Transplant Proc 1983; 15:1292-1296.

5. Starzl TE, Groth CG, Brettschneider L. An everting technique for intraluminal vascular suturing. Surg Gynecol Obstet 1968; 127:125-126.

6. Starzl TE, Groth CG, Brettschneider L, et al. Orthotopic transplantation of the human liver. Ann Surg 1968; 168:392-415.

7. Starzl TE, Schneck SA, Mazzoni G, et al. Acute neurological complications after liver transplantation with particular reference to intraoperative cerebral air embolus. Ann Surg 1978; 187:236240.
8. Calne RY. A new technique for biliary drainage in orthotopic liver transplantation utilizing the gall-bladder as a pedicle graft conduit between the donor and recipient common bile ducts. Ann Surg 1976; 184:605-609.

9. Denmark SW, Shaw BW Jr, Griffith BP, Starzl TE. Venousvenous bypass without systemic anticoagulation in canine and human liver transplantation. Surg Forum 1983; 34:380-382.

10. Griffith BP, Shaw BW Jr, Hardesty RL, et al. Veno-venous bypass without systemic anticoagulation for human liver transplantation. Surg Gynecol Obstet, in press.

11. Greenwood M. The errors of sampling survivorship tables. In Appendix 1, Reports on Public Health and Statistical Subjects, No. 33. London: His Majesty's Stationery Office, 1926.

12. Pappas G, Palmer WM, Martineau GL, et al. Hemodynamic alterations caused during orthotopic liver transplantation in humans. Surgery 1971; 70:872-875.

13. Moore FD, Wheeler HB, Demissianos HV, et al. Experimental whole organ transplantation of the liver and of the spleen. Ann Surg 1960; 152:374-387.

14. Starzl TE, Kaupp HA, Brock DR et al. Reconstructive problems in canine liver homotransplantation with special reference to the post-operative role of hepatic venous flow. Surg Gynecol Obstet 1960; 111:733-743.

15. Starzl TE, Marchioro TL, Huntley R, et al. Experimental and clinical homotransplantation of the liver. Ann NY Acad Sci 1964; 120:739-765.

16. Starzl TE, Groth CG, Brettschneider L, et al. Extended survival in 3 cases of orthotopic homotransplantation of the human liver. Surgery 1968; 63:549-563.

17. Kamada N, Calne RY. Orthotopic liver transplantation in the rat. Transplant 1979; 28:47-50.

18. Monden M, Barters RH, Fortner JG. A simple method of orthotopic liver transplantation in dogs. Ann Surg 1982; 195:110-113.

19. Starzl TE, Marchioro TL, von Kaulla K, et al. Homotransplantation of the liver in humans. Surg Gynecol Obstet 1963; 117:659676.

20. Calne RY, McMaster P, Smith DP, et al. Use of partial cardiopulmonary bypass during the anhepatic phase of orthotopic liver grafting. Lancet 1979; 2:612-614.

21. Aldrete J, Clapp HW, Starzl TE. Body temperature changes during organ transplantation. Anesth Analg 1970; 49:384-388.

\section{DISCUSSION}

Dr. William V. MCDermott, JR. (Boston, Massachusetts): First I would like to congratulate the American Surgical Association on its perception and recognition of excellence.

Before commenting directly on this excellent report from Pittsburgh of an enormous investment of time and effort, I would like to express the great appreciation of our liver transplant team at the New England Deaconess Hospital to Drs. Shaw, Starzl, and their associates for the tremendous assistance and advice that they provided us during the phase of training and orchestration of our liver transplant program, which is so vital to successful initiation of such a program.

Above and beyond the call of duty, both Dr. Shaw and Dr. Starzl came to Boston on the occasion of our first transplant a year ago for support and advice, which to us was a remarkable evidence of collegiality in the world of surgery.

With these initial comments, I would like to reemphasize the important role that venovenous bypass, as you have heard described, plays in the orderly completion of the complex set of technical maneuvers required in orthotopic transplantation.

During the past year, we have performed 12 orthotopic transplants, using the venovenous bypass. Early in our experience, the bypass was abandoned in one of the operations because of technical problems; and in contrast to all the other cases, obvious hemodynamic problems developed, with hypotension, with a fall in the cardiac output to 0.9 $1 /$ min during the anhepatic phase; there was also vigorous retroperitoneal bleeding, and a significant delay in graft function after surgery, all of which, anecdotally at least, we attributed to the nonuse of the bypass.

Complications of the venovenous bypass have been, so far, limited to the development of iliofemoral thrombosis in two patients in our early experience, a problem that has been since obviated by technical modifications in the insertion of the Gott shunt entirely through a previously dilated saphenous vein. Routine postoperative Doppler studies since then have shown no further venous thrombotic problems.

Our impression, therefore, in these initial 12 cases would confirm the much larger experience described by Dr. Shaw, that the venovenous bypass maintains a stable hemodynamic state during the anhepatic phase, is critical in the reperfusion phase of hepatic implantation and contributes significantly to the early postoperative function of the transplanted liver.

In closing, we are all in debt to the tremendous contributions of Dr. Starzl, Dr. Shaw, and their colleagues during this period of development of what I think is now a very acceptable addition to our clinical surgical armamentarium. 
DR. B. W. SHAW, JR. (Closing discusison): Dr. McDermott reminded me I should speak a little bit about complications. We have not seen any evidence of deep venous thrombosis in our patients, and I think the reason is because, very early on, rather than doing a cutdown on the femoral vein, we used the saphenous vein. It very readily accepts in almost all patients a $7-\mathrm{mm}$ Gott shunt.

And the axillary vein-we have not looked for a deep venous thrombosis in the axillary vein, except in two cases of acute arm swelling, and in both of those situations we did not have Doppler evidence of thrombosis of the axillary vein. There have been no instances of pulmonary emboli that we are aware of, and we monitor these patients very closely in the operating room for evidence of that.

I might mention that recently we have had occasion to operate on two patients with Budd-Chiari, both of whom were female, who had complete occlusion of the vena cava for its entire length up to the hepatic veins. The latter patient that we did also had a complete thrombosis of the portal vein.

We attempted to use bypass in both of these patients, and I think our experience with that leads me to conclude that bypass in the case of acute Budd-Chiari should not be used. We essentially went on bypass with one patient, and then experienced decrease in flow, which led us to take the patient off bypass. In both situations, the sewing in of the graft was done without bypass. So I think that acute BuddChiari may be an exception to the routine use of this procedure in all adult patients.

As far as pediatric patients are concerned, there are certainly many situations where it would offer an advantage in those patients as well. Right now, we are limited by the practicality with the current apparatus.

The experience in the dog laboratory that defined the lower limit of flow as 1 liter per minute is based on not using any heparin-bonded shunts. We simply added the heparin-bonded shunts when we began to use it clinically, because it was more convenient, and because we thought it might add some measure of safety.

I think if we can get a heparin-bonded system, which we are now working on, that is smaller and will work in children, there are going to be a number of pediatric patients who will also benefit from this technique. 